as a keen mountaineer and rock climber as well as geographer. A visit to East Greenland as a member of Mr. J. M. Wordie's expedition of 1926 confirmed these interests. More recently he has analysed longperiod temperature records in the north of England and revealed the gradual warming of our winters since 1820. The close resemblance between these changes and those for Stockholm suggests that this matter is of far more than local significance. In these early records Mr. Manley sees a valuable source of information that may throw light on the greater climatic changes of the Pleistocene Ice Age. Mr. Manley is, too, a keen but balanced advocate of the geographer's contribution to meteorology. This was the theme of his second presidential address to the Royal Meteorological Society. The Buchan Prize in 1943, the Symons Lecture in 1944, and the Murchison Grant of the Royal Geographical Society in 1947, all marked Mr. Manley's contributions to climatology ; but his papers also include other branches of geography, particularly the history of cartography. Mr. Manley remained at Cambridge long enough to see the University give somewhat belated recognition to meteorological studies by setting up a Meteorological Committee, of which he was the first secretary.

\section{Iron and Steel Institute Awards}

THE Council of the Iron and Steel Institute has made the following awards: Bessemer Gold Medal for 1948, to Mr. W. J. Dawson, formerly of Hadfield's, Ltd., in recognition of his contributions to the de. velopment of steel castings and to the production of alloy and heat-resisting steels; Sir Robert Hadfield Medal for 1948, to Mr. A. Preece, reader in metallurgy in the University of Leeds, in recognition of his researches on the scaling and on the overheating and burning of steel; Williams Prize for 1947, to Mr. R. Fowler, of Richard Thomas and Baldwins, Ltd., for his paper on "Blowing out a Blast-Furnace", printed in the Journal of the Iron and Steel Institute, 155, 513 (1947). The presentations will be made on May 5 during the annual general meeting of the Institute.

\section{American Institute of Biological Sciences}

AN American Institute of Biological Sciences has recently been established. The rapid advance of the biological sciences and their impact on human welfare have created new problems relating to the development and application of those sciences. During recent years many biologists have recognized that the biological sciences suffer from the lack of a service organisation, which would help the various biological societies to discharge more effectively those functions which are of common concern to them all, but which they cannot adequately exercise as individual societies. The new organisation is designed to fill this need as well as to serve the biologica] sciences in other ways. A governing board has now elected the officers and an executive committee. Recognizing the potential importance of this new undertaking for the advancement of the biological sciences, and through them for all biologists, the U.S. National Research Council has not only endorsed the programme, but has also agreed to make available the general services of the Council. As a part of the National Research Council, the Institute will also provide biologists with an agency through which they can maintain close relations with govern. mental activities and with other fields of science represented within the Council.

\section{The Fall Webworm of North America in Europe}

Dr. PaUl Surányi, University of Agricultural Sciences, Budapest, states in a letter that the first specimen of the moth of fall webworm (Hyphantria cunea Drury) to be caught in Europe was found in the vicinity of the Danubian Free Port of Budapest in 1940. Hitherto it has not been observed outside the United States and Canada. The way it has increased shows that its caterpillar has found very favourable conditions of life in Europe. Nests of the caterpillars were first observed in 1943 ; since then it has increased rapidly, and during 1945-46 it did considerable damage in orchards and on various trees. It was distributed over a semicircular area with a diameter of $80 \mathrm{~km}$. in 1946, which has now increased to $200 \mathrm{~km}$. Indeed, this destructive insect has overrun two-thirds of Hungary, has reached the borders of Czechoslovakia and Yugoslavia, and is approaching those of Austria and Rumania. North of Budapest it is seldom observed, due probably to the prevailing north to north-west wind. Its favourite feeding-plants-the same as in North America-are Acer negundo L. and Morus alba L., from the latter of which it strips the leaves in groves and along the highways. But it feeds on all fruit-bearing and garden trees, and-what is much more dangerous-it has established itself also in the woods. Fifty-eight species belonging to different genera are known to be food plants; they include oak (Quercus spp.), alder (Alnus glutinosa L.), black locust, (Robinia pseudacacia L.), common stinging nettle (Urtica dioica L.), cabbage (Brassica oleracea L.), and also horseradish (Armoracia lapathifolia Gilibi). Two generations of the fall webworm normally hatch in a year. Its swift spread seems to be due not only to suitable conditions, but also to the fact that, so far as Dr. Surànyi's experience goes, the caterpillars are seldom attacked by European parasites.

\section{Mechanics of Packings of Granular Material}

IN view of the many technological fields where an understanding of the properties of granular materials is fundamental, it is surprising that there has been little systematic investigation, the present inchoate body of knowledge being derived from ad hoc studies. In reviewing the more recent literature, D. R. Hudson (Machinery, 70, 617, 681; 1947) discusses work on packings of material in bulk carried out by investigators in the fields of geology, fuel technology, the ceramic industry, civil and chemical engineering, and powder metallurgy. This widespread interest may account partly for the diffuse study in industrial research. On the academic side the present preoccupation with the fine-structure of matter has led to the neglect of Osborne Reynolds' pioneer work on packings, undertaken in the 1890's in an attempt to provide a mechanical explanation of the universe.

Hudson's review is more concerned with the structure and characteristics of a compacted granular bed-the voidage and number of interparticle contacts and their dependence on particle size and size distribution, the relative size and the shape of the container-than with the effect on the structure of deformation of the packing, which is of especial importance in earth pressure theory, in the study of handling and conveying mechanisms and in the design of hoppers, bunkers and silos, where Reynolds' 
principle of dilatancy provides a key to the construction of force diagrams. Nevertheless, Hudson emphasizes the complex character of packings as opposed to the ordered structures of crystallography and the random assemblies of statistical mechanics, and implies the impossibility of deriving a satisfactory theory of packings as an extension of the geometry of ideal ordered or disordered arrangements of equal spheres.

\section{Foraminifera}

To British marine zoologists, more particularly those dealing with the North Sea area, Hans Högland's work on the foraminifera in the Gullmar Fjord and the Skagerak (Zool. Bidrag f. Uppsala, 26 ; 1947) should prove very useful. While it includes only thirteen families of the Foraminifera it has reached formidable size, for in it are discussed in detail 133 species and varieties, and the remaining families are likely to contain nearly as many forms. It is fortunate that the author has had access to Gcës' material, for it formed the basis of our knowledge of the Foraminifera in this area. Since the publication of Gcøs' work more than fifty years ago, a great deal has been done on this group with much alteration of classification and taxonomy. In class. ification, Högland has adopted a somewhat conservative attitude and has based his upon that of Cushman (1933), but he has been more drastic in the matter of nomenclature. Where the data appeared adequate the work has been carried out quantitatively, and here striking differences resulting from various collecting techniques are manifest. As an example, we have one form, Bulimina fusiformis, where the core sampler gave a total of 5,500 specimens and the corresponding sledge-net sample gave only thirty. It is interesting to note that the author was attracted to the study of this group from the ecological point of view, but soon realized that ecology must be based upon sound identification and taxonomy : hence the 32 splendid plates and the 303 figures which illustrate the range of variation within what the author regards as valid species.

\section{Scientific Research in India}

A REPORT has been issued, in the Proceedings of the National Institute of Sciences of India (11, Pt. 4, 161-370), of a symposium on the centralization of scientific research in India, held on July 23, 1945, which was opened by the president of the Institute, Mr. D. N. Wadia. Mr. Wadia, after referring to the necessity of taking into account the effect of a central policy on the work of various scientific institutions in India, emphasized the benefits likely to accrue from a central organisation for scientific research. Central direction should not involve too much inter. ference or loss of independence in the pursuit of science. Dr. J. A. Dunn supported the liaison and co-ordination of research by a single member and department of a central government as the only course which could be wisely pursued, but he was not in favour of the whole of the country's research being brought under one department. He outlined a scheme for a central council for scientific and industrial research, with provincial and State councils, a committee of central scientific departments and other boards and committees as required. Dr. A. C. Ukil advocated the co-ordination of researches but without power of interference with the findings of the National Research Council, which should be the supreme central body to organise research throughout the country; no Government department, he said, should be allowed to maintain its separate research section, independent of the guidance of that Council.

Prof. J. N. Mukherjee also emphasized that the different units dealing with various aspects of research need not all be under one authority; centralization of scientific research should not mean centralized control under one government department. The autonomy of universities and other non-official institutions should not be circumscribed. Prof. M. N. Saha strongly supported Prof. Hill's scheme, as did Prof. P. C. Mahalanobis, with some warning on the danger of bureaucracy and departmentalism creeping in. He urged that the National Institute should press for the fullest possible association with the work of the proposed department of the learned societies, universities and scientific institutions. Prof. S. P. Agharkar thought that the real difficulties in India were encountered at the policy-making level. Dr. G. J. Fowler set forth points for and against centralization and urged the need for care lest organisation crippled individual initiative. Dr. Nazir Ahmad indicated some practical difficulties, but supported the co-ordination of research so as to avoid overlapping, to accelerate the pace of research and to use and to train talent to the best advantage. Dr. J. N. Roy considered that the National Institute of Sciences should concern itself solely with the availability of adequate funds for scientific research, and that the question of organisation was outside its sphere. A report of the symposium is being sent to all Departments of the Government of India with an expression of opinion from the fellows of the Institute as to the necessity of there being one Department of the Government of India concerned with the formulation of policy, determination of priority and administration of all funds earmarked for scientific research.

\section{Radio and Electrical Research in Canada}

THE National Research Council of Canada has announced the formation of a Radio and Electrical Engineering Division under Mr. B. G. Ballard. This new Division is a consolidation of work formerly carried on in the Division of Physics and Electrical Engineering, and has become necessary on account of the great expansion of research activities in the fields of electronics and electrical engineering consequent upon the advances in radio and related techniques during recent years. There are at present some 230 members of staff in the Division, including about fifty scientific personnel, and their work includes various aspects of radar, radio-physics, high-voltage electrical engineering, and the general application of electronics for military as well as for civil purposes.

Mr. Ballard, the new director of the Division, after graduating from Queen's University, Canada, obtained five years industrial experience with the Westinghouse Electric and Manufacturing Co. at East Pittsburgh. He joined the staff of the National Research Council in 1930, and has been engaged continuously in radio and electrical engineering research. His activities during the War were largely devoted to the development of mine-sweepers for enemy magnetic mines and the protection of ships against these mines; in recognition of his contributions in this field, Mr. Ballard was made an O.B.E. in 1946. 